\title{
The Script Concordance Test
}

Can. J. Neurol. Sci. 2009; 36:272-273

Clinical judgment is the ability to make appropriate decisions in uncertain or ambiguous situations. ${ }^{1}$ The role-model clinicians who we all admire, wish to emulate and want to look after us or our families when we are ill are the physicians who have the ability to do this. It is this capacity, to reason in contexts of uncertainty and to solve ill-defined problems, that defines professional competence. ${ }^{2}$ The knowledge needed to successfully reason in these contexts is called professional knowledge. ${ }^{3}$

As clinical teachers we are continually asked to evaluate trainee's, (medical students or residents) clinical judgment (i.e. clinical decision making abilities). Most of us do this on the basis of very individual and subjective criteria which are influenced by both the content and context of the clinical encounters under which we have observed the trainee. While it may be easier to decide that the trainee is doing well, this is not always the case in those instances where we believe the trainee's performance is suboptimal or unsatisfactory. In these circumstances, we would all like to have some type of objective measure to help us out. The Script Concordance Test (SCT) is such an instrument.

Although the SCT has been the subject of more than 20 publications since it was initially described in $2000^{4}$, this may be the first time that many of the readers of the Journal have heard about it since most of the publications have focused on its use in surgical disciplines. This should not be surprising in light of the fact that Dr. Charlin, one of the key developers of this methodology is a surgeon educator. Clinical teachers and educators are referred to two 2007 publications for an in-depth review of the topic. ${ }^{5,6}$

In their paper, Lubarsky et $\mathrm{al}^{1}$, elegantly outline how they developed the SCT for use in neurology. They have shown that it can be delivered on-line and demonstrated its validity by assessment of its psychometrics. Also, we learned that it was developed without the need for extensive new resources or excessive time.

Beyond being a "nice" study, one might ask, "Does this report have practical relevance for clinical neuroscience educators in Canada and elsewhere"? My answer is a definite yes for a number of reasons.

First, it introduces an evidence-based tool into our evaluation armamentarium for the assessment of clinical decision making.

Second, the SCT has great potential as a tool for use in the formative evaluation of trainees from medical students at the clerkship stage to residents at all levels. Armed with the results of the SCT performance, the educator would be able to sit down with the trainee, and by questioning, determine what the trainee was thinking when an incorrect response was chosen. This approach will help clarify why the particular choice was made and even more importantly provide the teacher with information that could be used to help the trainee improve their clinical decision making capabilities.
Third, the SCT could be used as a tool for summative evaluations at different levels of training, assuming that the problems being assessed are based on the objectives that must be met for the particular level of training.

Finally, the SCT could be used as a self-assessment tool by trainees at any time to evaluate how they are doing?

Since this is a good test aimed at assessing a critically important skill how might we move forward to ensure that it becomes a widely adopted assessment tool in Canada?

Is this likely to happen if it is left up to the initiative of individual undergraduate education leaders and neurology training program directors? I think not! However, I believe that some type of national initiative focused on this task would be successful.

In terms of moving this forward for neurology education in Canada, my suggestion would be that the Canadian Neurological Society, through its Education Committee (EC), takes on, as an educational priority, an initiative to support and coordinate the development of the SCT as an on-line evaluation tool for assessment of neurological clinical judgment in Canada. The EC could move this priority forward by establishing a special Task Force, with representation from both undergraduate and postgraduate neurological educators, whose terminal objective would be to develop a large, standardized bank of test items. These items could be made available for on-line use in assessment of clinical judgment of medical students and neurology trainees at all levels in all educational institutions in Canada.

In addition to providing a technique for assessment of achievement of different levels of clinical decision making in medical students and trainees, such an on-line data base could serve as a rich resource to begin to answer research questions such as:

1. How well are our clinical clerks (at each medical school) performing in comparison to the cohort of clinical clerks across the country?

2 . Does the performance of our residents indicate a need to relook at the type of clinical rotations they are following?

3. Can we demonstrate improvement in resident clinical decision making based on using the results of formative testing for residents who seem to be having difficulty?

In clinical practice the buzzword is "evidence-based practice". Unfortunately when it comes to education much of what we do is not evidence based. The SCT provides us with the opportunity to apply an "evidence-based practice" to our educational assessment. We should "get on" with its adoption. 


\section{REFERENCES}

1. Lubarsky S, Chalk C, Kazitani D, Gagnon R, Charlin B. The script concordance test: a new tool and assessing clinical judgment in neurology. Can J Neurol Sci. 2009;36:326-31.

2. Johnson EJ. Expertise and decision under uncertainty: performance and process. In: Chi MTH, Glaser R, Farr MJ, editors. The nature of expertise. Hillsdale NJ: Lawrence Erlbaum; 1998. p. 409-25.

3. Schön DA. The reflective practitioner: How professionals think in action. New York: Basic Books; 1983.
4. Charlin B, Roy L, Brailovsky C, Goulet F, van der Vleuten C. The script concordance test: a tool to assess the reflective clinician. Teach Learn Med. 2000;12(4):189-95.

5. Charlin B, van der Vleuten C. Standardized assessment of reasoning in contexts of uncertainty. Eval Health Prof. 2007;27(3):304-19.

6. Charlin B, Boshuizen HPA, Custers EJ, Feltovich PJ. Scripts and clinical reasoning. Med Educ. 2007;41:1178-84. 